\title{
LA CONSAGRACIÓN DEL PRINCIPIO DE SEGURIDAD JURÍDICA COMO CONSECUENCIA DE LA REVOLUCIÓN FRANCESA DE 1789
}

\author{
José O. López Oliva*
}

\author{
Fecha de recibido: 15 de septiembre de 2011 \\ Fecha de aprobación: 21 de noviembre de 2011 \\ Artículo de Reflexión
}

\begin{abstract}
Resumen
Con anterioridad a la Revolución Francesa de 1789 no se aplicaba el principio de Seguridad Jurídica, por cuanto se presentaban irregularidades al impartir justicia a los ciudadanos, marcadas en una excesiva parsimonia en los procesos por parte

de los jueces quienes eran designados de acuerdo a las conveniencias del reino. De igual manera, los juzgadores decidían las controversias basados en los intereses del monarca y los miembros del reino, sumado al temor de aquellos porque al no seguir las instrucciones del rey, eran castigados con la muerte. En respuesta a las mencionadas anomalías, nace la Revolución Francesa que trajo consigo la Declaración de Derechos de 1.789, la Constitución de 1.791 y el Código Civil Francés de 1.804, en los cuales se implementa el principio de Seguridad Jurídica. Uno de los fines primordiales de la citada revolución era organizar el sistema jurídico que operaba en aquella época, ubicando al individuo como sujeto de derechos sin discriminación alguna, y donde prime la supremacía de sus derechos.
\end{abstract}

\section{Palabras clave}

revolución francesa, despotismo, principio de Seguridad Jurídica, legalidad, igualdad.

\section{CONSECRATION OF THE PRINCIPLE OF LEGAL CERTAINTY AS A RESULT OF THE FRENCH REVOLUTION OF 1789}

\begin{abstract}
Before the French Revolution of 1789 did not apply the principle of legal certainty, since the irregularities to deliver justice to citizens, had marked by the excessive parsimony in the processes by of judges who were appointed according to the conveniences of the kingdom. Similarly, the judges to decide disputes were based on the interests of the monarch and
\end{abstract}

Docente investigador TC Universidad Militar Nueva Granada. Director del Área de Derecho Privado. Magister en Derecho con enfoque en Derecho de la Responsabilidad y Seguros de la Universidad de los Andes, Magister de la Universidad Carlos III de Madrid (España), Especializado en Derecho Comercial de la Universidad Pontificia Bolivariana de Medellín, Derecho Penal y Probatorio de la Universidad del Rosario. Consultor y conferencista a nivel nacional e internacional, profesor Universitario de Pregrado y Postgrado, Docente certificado a nivel internacional por la Life Office Management Asociation, Inc - Loma con sede en Atlanta-Georgia (USA). Ha escrito y publicado textos de contenido jurídico. Línea de investigación grupo Derecho Público, Facultad de Derecho, UMNG. Correo electrónico: jose.lopez@unimilitar.edu.co 
the members of the kingdom, together with the fear that not following the instructions of the king, were punished with death. In response to the above anomalies, was born of the French Revolution brought about by the 1789 Bill of Rights, the Constitution of 1791 and the French Civil Code of 1804, in which implements the principle of legal certainty. One of the primary purposes of that revolution was to organize the legal system that operated at that time, placing the person as subject of rights without discrimination, and where prime supremacy of their rights.

\title{
Keywords
}

French revolution, despotims, principle of legal certainty, legalicy, equity.

\section{A CONSAGRACIÓN DO PRINCÍPIO DE SEGURANÇA JURÍDICA COMO CONSEQUÊNCIA DA REVOLUÇÃO FRANCESA DE 1789}

\begin{abstract}
Resumo
Com anterioridad à Revolução Francesa de 1789 não se aplicava o princípio de Segurança Jurídica, porquanto se apresentavam irregularidades ao dar justiça aos cidadãos, marcadas numa excessiva parcimónia nos processos por parte dos juízes quem eram designados de acordo às conveniencias do reino. Do mesmo modo, os juzgadores decidiam as controvérsias baseados nos interesses do monarca e os membros do reino, somado ao temor daqueles porque ao não seguir as instruções do rei, eram castigados com a morte. Em resposta às mencionadas anomalías, nasce a Revolução Francesa que trouxe consigo a Declaração de Direitos de 1.789, a Constituição de 1.791 e o Código Civil Francês de 1.804, nos quais se implementa o princípio de Segurança Jurídica. Um dos fins primordiais da citada revolução era organizar o sistema jurídico que operava naquela época, localizando ao indivíduo como sujeito de direitos sem discriminação alguma, e onde prime a supremacía de seus direitos.
\end{abstract}

\section{Palavras-chave}

Revolução francesa, despotismo, princípio de Segurança Jurídica, legalidade, igualdade.

"No hay en Francia una autoridad superior a la de la ley. El rey no reina sino por ella, y es en nombre de la Ley que él puede exigir obediencia" Constitución Francesa de 1971 art. 3, Cap. II, título III

\section{INTRODUCCIÓN}

El presente escrito, es resultado de un trabajo exploratorio de revisión donde se analiza e integra el resultado de una investigación bibliográfica, mediante la compilación y sistematización de los documentos encontrados sobre el tema objeto de investigación; tema relacionado con la consagración del principio de Seguridad Jurídica implementado como resultado de la Revolución Francesa. El presente trabajo exterioriza el siguiente problema de investigación: ¿operó el principio de Seguridad Jurídica ${ }^{1}$ con anterioridad a la Revolución Francesa?

1 Para ampliar el tema relacionado con el derecho, las normas y los principios, Cfr. SÁNCHEZ DE LA TORRE, A.: El Derecho en la aventura europea de la libertad. Editorial Reus. Madrid. 1987. Igualmente, Cfr. ALEXI, Robert. Una Discusión Sobre la Teoría del Derecho. Editorial Marcial Pons. Madrid. 2007. 
Para ello se presentarán (1) algunos conceptos sobre Seguridad Jurídica y se realizará (2) un breve análisis de los antecedentes de la Revolución Francesa, donde se evidenciará la ausencia del principio de Seguridad Jurídica; a continuación, (3) se hará referencia a la Declaración de Derechos de 1.789, donde se establecen disposiciones que consagran el principio de Seguridad Jurídica; (4) se indicando las consecuencias desde el punto de vista jurídico de la mencionada revolución, como son (4.1) la Constitución de 1.791 y (4.2) el Código Civil Francés de 1.804, donde igualmente se aborda el principio de Seguridad Jurídica, imponiendo límites al poder de los gobernantes de la época; para finalizar (5) se expondrán unas breves conclusiones.

\section{EL PRINCIPIO DE SEGURIDAD JURÍDICA}

La Seguridad Jurídica es un principio conocido en el área del derecho, que representa la certeza del conocimiento de todo lo previsto como prohibido, mandado y permitido por el denominado poder público. La palabra seguridad proviene de securitas, la cual deriva del adjetivo securus (de secura) que, significa estar seguros de algo y libre de cuidados. En resumen, la Seguridad Jurídica es la certeza que tiene el individuo de la permanencia de su situación jurídica y no será modificada sino por procedimientos regulares y conductos establecidos de manera previa y clara (Sánchez de la Torre, 1987) por el derecho.

Derecho entendido no solo como el conjunto de normas, sino también principios como el de Seguridad Jurídica, así como valores que precisan una estructura reglamentaria cuya finalidad es el cumplimiento de tres aspectos fundamentales: garantizar la Seguridad Jurídica (no reconocida antes de la Revolución Francesa), garantizar el respeto a los derechos humanos y a la libertad y cooperar con el progreso, la justicia y la paz social (Sánchez de la Torre, 1987) que necesitaban los franceses de la época (siglo XVIII) donde imperaba el despotismo.
Despotismo que es un tipo de régimen enmarcado en la imposición de la autoridad absoluta, no limitada por las leyes y una "justicia, dispersa entre la justicia real, miles de pequeñas justicias señoriales y las oficialidades religiosas" que generaron inconformidad en los ciudadanos franceses. (Pierre, 1985, p. 22).

En efecto, un gobierno déspota expide las leyes que más le convengan en un momento o situación determinada, sin ningún tipo de reparo e incluso, ni siquiera obedece a sus propias leyes. En este orden de ideas, una vez realizada la aproximación a la definición de despotismo que transgrede la Seguridad Jurídica, se resalta la incuestionable relación existente entre derecho y poder, donde la ley está definida en los intereses del gobierno y no en la consagración de un Estado que constituya un fin en sí mismo, consagrado como una "asociación política consistente en la conservación de los derechos naturales e imprescriptibles del hombre" (Soboul, 1987, pp. 98 y 99).

El gobierno déspota de la Francia de aquella época y "las contradicciones irreductibles de la sociedad del Antiguo Régimen habían llevado a la revolución desde hace mucho tiempo a la orden del día. Las fluctuaciones económicas y demográficas, generadoras de tensión y que en las circunstancias de la época escapaban a toda acción gubernamental, crearon una situación revolucionaria. Contra un régimen que su clase dirigente era incapaz de defender, se alzó la mayoría de la nación, confusa o inconsciente" (Soboul, 1987, p. 193) que ansiaba igualdad, justicia y Seguridad Jurídica "signada por el principio de la supremacía del legislador, que representaba a la Nación" (Brewer-Carias, 2004, p. 188).

Era de vital importancia el establecimiento de principios, incluido el de la Seguridad Jurídica, proclamados en 1789 y "que constituyen el núcleo racional de la ideología de los Derechos del Hombre" (Soboul, 1987, p. 73), tan deseados por el ciudadano francés a quien "le favorecía tanto en la ofensiva contra la sociedad del Antiguo Régimen, puesto que excluía la existencia del 
privilegio y de una jerarquía social jurídicamente constituida" (Soboul, 1987, p. 72), que promueva la consagración de sus derechos, los cuales tuvieron que ser reclamados mediante una revolución.

\section{ANTECEDENTES DE LA REVOLUCIÓN FRANCESA}

Es relevante en principio, ubicarse dentro del contexto histórico antecedente a la Revolución Francesa. En efecto, en el período comprendido en Francia entre 1.643 y 1.715 bajo el gobierno monárquico de Luis XIV, proliferó un completo despotismo (Fioravanti, 2000, p. 56), tal como se señaló, entendido como la centralización desmedida del poder, en este caso en manos del monarca, quien lo justificaba apoyado en el argumento de la divinidad del reino. El régimen dominante de aquella época, se muestra en la afirmación realizada por dicho soberano quién expresó abiertamente: L'Etat, c'est moi ${ }^{2}$ (El Estado soy yo).

El despotismo, como se indicó precedentemente, es un régimen que no reconoce ni obedece las leyes y menos si no le convienen; es más, las leyes son estructuradas por el régimen monárquico en este caso, de acuerdo a sus conveniencias; el despotismo limita y dificulta la consagración del principio de Seguridad Jurídica y "el desarrollo de la soberana potestad pública" (Fioravanti, 2000, p. 56).

A continuación, entre los años de 1.715 y 1.774 reinó Luis $\mathrm{XV}$, quién con su mediocre liderazgo provocó una intensa crisis en todos los aspectos (Ciuro, 2007, p. 3), generando un profundo trance en los órdenes políticos, legales y económicos. El régimen totalitario con imposiciones como el pago del $30 \%$ del sueldo devengado por los súbditos a favor de los nobles, confluyó en la

2 Cabe resaltar, que los monarcas eran coronados y proclamados por los mandos eclesiásticos, bajo la apología del derecho divino inherente a la calidad de reyes. Esto les permitía actuar con absoluta arbitrariedad.
Revolución Francesa enmarcada en una "cultura revolucionaria de los derechos y libertades," (Fioravanti, 2000, p. 71). que intentó dar prioridad a aquellos por encima del poder del soberano (Fioravanti, 2000, p. 77).

En seguida, el monarca imperante dentro del período en que se llevó a cabo la referida revolución comprendida entre 1.779 y 1.789 , fue Luis XVI (1.774-1.793) quien si bien es cierto gobernó sin tanto autoritarismo como sus predecesores, no hubo compasión por los revolucionarios y fue decapitado. Un breve resumen del desarrollo cronológico de los acontecimientos que precedieron la Revolución Francesa se presenta de la siguiente manera: "todo el proyecto revolucionario se construye a través de la contraposición radical al pasado del antiguo régimen, en la lucha contra la doble dimensión del privilegio y del particularismoy, por lo tanto, a favor de los nuevos valores constitucionales: fundamentalmente, los derechos naturales individuales y la soberanía de la nación." (Fioravanti, 2000, p. 59).

Asimismo, es importante resaltar que dentro de los períodos antes aludidos, se presentaban un sinnúmero de irregularidades en el momento de impartir justicia, lo que generaba un intenso riesgo para la Seguridad Jurídica y por ende para la garantía de los derechos de las personas y de la soberanía de la nación. Entre las irregularidades indicadas se encontraban: de un lado, una excesiva parsimonia en los procesos y de otro lado, el hecho que los censores eran favorecidos en sus cargos de acuerdo a las conveniencias del reino (Portalis, 1997, p. 9). Por consiguiente, era el monarca quien en su infinita omnipresencia y omnipotencia, decidía indirectamente sobre el resultado del proceso, de acuerdo a sus intereses individuales o los de su grupo de asesores. Dicho monarca "además de ser fuente de toda justicia y de toda legislación...era también fuente de toda autoridad y gobierno" (Brewer-Carias, 2004, p. 129), lo que generaba incertidumbre en los ciudadanos franceses porque su situación jurídica podía ser modificada en cualquier momento. 
Los juzgadores, cuyos cargos en esa época eran heredados (con lo que el principio de Seguridad Jurídica era inoperante), no contaban con pulso firme al proferir sus fallos, porque les invadía el miedo, por cuanto al no interpretar en debida forma los intereses del soberano, pudieran ser castigados inclusive hasta con la muerte al no acoger la "Lex Rex" (Brewer-Carias, 2004, p. 128); este término "era una expresión que se utilizaba para expresar que el rey era la ley; que era la ley viva, en sí misma, por lo que no estaba ligado a las leyes dictadas por sus antecesores."

Lex Rex, generaba incertidumbre para los súbditos, porque en las actuaciones judiciales ellos no entendían ni conocían lo permitido o lo prohibido por las normas, caracterizadas por su propensa confusión; todo esto representaba, claramente, una irrebatible violación al principio de Seguridad Jurídica y un abuso del poder sin límites, porque se estableció que: "Uno de los principios de las leyes del reino era el de la inviolabilidad del monarca, en tanto su poder provenía de Dios. De ahí que este poder fuera consagrado, usual y formalmente por el representante de Dios en la tierra, el Papa." (Brewer-Carias, 2004, p. 126).

Es evidente, en suma, que existía una propensión a que los fallos se hallaran ajustados a las conveniencias del monarca, con el uso clandestino de los recursos, como lo señala el tratadista Diego López Medina (2006, pp. 8-9), de la costumbre y la jurisprudencia, para lograr sus fines non sánctus.

En lo atinente a este tema, López Medina hace una interesante referencia a la utilización, en aquella época, de la costumbre y la jurisprudencia como se indicó anteriormente, con el fin de manipular los fallos ligados al antojo y conveniencia de la realeza, en una clara infracción al principio mencionado. Señala el citado autor:

\section{(...) la ley tiene predominancia total frente} a la costumbre y la jurisprudencia. En Francia, al menos, la jurisprudencia y la costumbre eran formas de creación del derecho propias del detestado ancien régime. Los códigos post-revolucionarios, por tanto, prohíben su utilización como fuentes de derecho e impiden que estas fuentes del derecho antiguo usurpen la voluntad general soberana que solo se puede expresar por medio de la ley. En especial, la costumbre y la jurisprudencia tan solo representaban voluntades politicas particulares y tendían a conceder $y$ preservar derechos particulares provenientes del status de las personas, violando con ello las máximas de generalidad, impersonalidad e igualdad propias del derecho post-revolucionario y propias de la concepción ilustrada del derecho que se expandía por occidente.

Como respuesta a estas irregularidades, nacen según afirmación de Fioravanti, "las revoluciones (como la francesa, que) señalan de distinto modo $y$ con diferente intensidad el momento en que en el centro del ordenamiento jurídico se pone al individuo como sujeto único de derecho, que -más allá de las viejas discriminaciones del estamento- es ahora titular de derechos en cuanto tal, como individuo." (Fioravanti, 2000, p. 55).

Por ello, la Revolución Francesa se afirmó en la supremacía de los derechos individuales y la primacía de la soberanía de la nación y de sus legisladores, como una fuente para combatir el pasado y específicamente, "un pasado de antiguo régimen donde la estructura en sentido estamental de la sociedad, de los derechos y de los poderes impedía, al mismo tiempo y en la misma medida, la afirmación de los derechos individuales y de un poder público claramente unitario." (Fioravanti, 2000, p. 58).

Derechos que se consagraron en artículos como el quinto de la Declaración de Derechos donde sale a la luz el principio de Seguridad Jurídica; esta norma señala:

Todo lo que no está prohibido por la ley no puede ser impedido, y nadie puede ser obligado a hacer lo que ella no ordena. Atribuye a la ley el formidable poder 
de prohibir, de impedir, de obligar y de ordenar; pero también, al mismo tiempo e inseparablemente, presta a los individuos la garantía basilar de que ninguno será coaccionado sino en nombre de la misma ley, en contra de la antigua realidad de los poderes feudales y señoriales. (Fioravanti, 2000, p. 58).

Motivados los revolucionarios franceses por el fortalecimiento de sus derechos, es que nace la declaración de éstos en 1.789.

\section{LA DECLARACIÓN DE LOS DERECHOS DE 1.789}

La Revolución Francesa trae consigo la Declaración de Derechos de 1.789 en contraposición al antiguo régimen; en aquella se consagran dos valores político-constitucionales: el individuo y la ley como expresión de la soberanía de la nación. (Fioravanti, 2000). Igualmente, disponía dicha declaración que ninguna corporación o individuo puede ejercer una autoridad que no emane expresamente de la ley, cuya supremacía "fue garantía de la igualdad, uno de los postulados básicos de la revolución." (Brewer-Carias, 2004, p. 188). Mediante la declaración referida, se fijan los parámetros de un modelo político que libera tanto al individuo como al mismo Estado; "este último manifestado ahora en los términos de la soberanía de la nación- (libre) de la presencia embarazosa de los viejos poderes feudales y señoriales," (Fioravanti, 2000, p. 58), que en unión con el monarca, atentaban contra el principio de Seguridad Jurídica.

La Declaración de Derechos fue la respuesta a la inconformidad generalizada del pueblo, que estaba cansado de las actuaciones judiciales, enmarcadas en la incertidumbre generada hacia los súbditos, quienes no entendían, ni conocían lo permitido o lo prohibido por las leyes ${ }^{3} y$ mucho

3 Para los efectos de este escrito tómese normas, leyes, preceptos legales, como lo mismo. menos, participaban en la creación de éstas; todo, representaba la evidente violación al principio de Seguridad Jurídica y un abuso del poder, donde "el rey era fuente de toda justicia hasta el punto en que no se concebía justicia alguna que no fuera impartida por el rey" (Brewer-Carias, 2004, p. 127).

El artículo sexto de la Declaración de Derechos estableció que "La Ley es la expresión de la voluntad general. Todos los ciudadanos tienen derecho a participar personalmente o a través de sus representantes, en su formación". Los ciudadanos entonces adquieren protagonismo, porque cuentan con la posibilidad de influir directa o indirectamente en la creación de las leyes, lo que genera estabilidad, continuidad (Fioravanti, 2000, p. 65) y Seguridad Jurídica en la post-revolución.

No obstante, "no era fácil gobernar en Francia después de 1789: la revolución no era solo un conjunto de principios nuevos que había que aplicar ahora respetando las reglas parlamentarias inventadas a medida que se hacían necesarias; era también una atmósfera política y moral de libertad incontrolable y espontáneamente violenta." (Pierre Bois, 1985, p. 53).

Se señala igualmente que "la Declaración de los Derechos libera al individuo de las antiguas ligaduras del señor-juez o del señor-recaudador, libera también al ejercicio del poder público en nombre de la nación de las nefastas influencias en sentido disgregante y particularista de los poderes feudales y señoriales" (Fioravanti, 2000, p. 74). Se argumenta de la misma manera que "la concentración de imperium en el legislador intérprete de la voluntad general aparece, en primer lugar, como máxima garantía de que nadie podrá ejercer poder y coacción sobre los individuos sino en nombre de la ley general y abstracta." (Fioravanti, 2000, p. 58).

En efecto, las antiguas uniones entre los jueces y el monarca, quien estructuraba las leyes a su acomodo, lesionaban el principio de Seguridad Jurídica y por ello la sociedad revolucionaria de la época reacciona con el fin de asegurar la 
garantía de sus derechos (Fioravanti, 2000, p. 74), que se consagrarían en la Constitución de 1.791 a la que se hace alusión en seguida. Como muestra, en el artículo 16 de la Declaración de Derechos enseña que "toda sociedad que no asegura la garantía de los derechos, ni determina la separación de los poderes, no tiene Constitución." (Fioravanti, 2000).

\section{LA CONSTITUCIÓN DE 1.791 Y EL CÓDIGO CIVIL FRANCÉS COMO IMPULSORES DEL PRINCIPIO DE SEGURIDAD JURÍDICA}

Una vez reseñadas las incidencias de la Revolución Francesa y la consecuente Declaración de Derechos en torno al principio de Seguridad Jurídica, se presentan las incidencias de la Constitución de 1.791 y el Código Civil Francés, que muestran disposiciones que fortalecen la implementación de la Seguridad Jurídica a favor de los ciudadanos franceses; esto, con el establecimiento de "diversos principios (que) tienen por finalidad garantizar la soberanía nacional (por cuanto) $<<$ toda sociedad en la que la garantía de poderes no esté determinada, carece de constitución > > (art. 16 constitución de 1971)" (Soboul, 1987, p. 99).

\subsection{La Constitución de 1.791}

En 1.791 fue promulgada la primera Carta Constitucional Francesa escrita; Constitución que se instituye como del pueblo soberano y donde se estableció que no había en Francia autoridad superior a la de la ley, algo pensado para el rey pero también para los jueces (Portalis, 1997, p. 9), por cuanto ellos obedecían irregularmente las directrices del soberano y con sustento en éstas proferían sus decisiones.

En concreto, la Revolución Francesa y la consecuente expedición de la Declaración de Derechos y posteriormente la Constitución, "no puede ni quiere conceder un papel garantizador importante a los jueces, porque parte de la experiencia histórica del Estado absoluto que la condena a ver a los jueces o como funcionarios del Estado o como...herederos de privilegios aristocráticos" (Fioravanti, 2000, p. 72) lo cual lesiona el principio de Seguridad Jurídica. "La constitución del 13 de septiembre de 1791, que fue la primera constitución europea moderna, configuraba sin embargo, un Estado monárquico, signado por la separación de poderes: el rey que conservaba el poder ejecutivo, el poder legislativo lo asumía la Asamblea, y el Poder Judicial, los tribunales"(Brewer-Carias, 2004, p. 172).

De igual forma, el monarca si bien es cierto era el jefe del poder ejecutivo, contaba por disposición de la Constitución, con facultades fuertemente debilitadas y por lo tanto ya no podía manipular a los jueces, lo cual garantizaba la aplicación del principio referido; el Rey entonces, era sometido a la ley establecida por el legislador (Fioravanti, 2000, p. 59); éste, debía garantizar a los pobladores, por expresa disposición de la carta constitucional, "el espacio suficiente para que los ciudadanos puedan ocuparse de su esfera privada, de los negocios, del comercio, de la familia, de los afectos," (Fioravanti, 2000, p. 64) y no teman por la violación del caro principio de Seguridad Jurídica.

Sin duda, se suscitaron en aquella época numerosos acontecimientos que influyeron tanto en la expedición de la Carta Magna Francesa, como del Código Civil Francés: “...los libros de Blackstone sobre las leyes criminales de Inglaterra o a través del lejano ejemplo del artículo 29 de la Magna Carta de 1225, del Acta de Habeas Corpus de 1679 o del Bill of Rights de 1628, también tenían en cuenta logros concretos como la abolición de la pena de muerte por el gran Duque de Toscaza" (Portalis, 1997, p. 9). Asimismo, "el Duque de la Rochefoucalud d'Enville había publicado la traducción de 1783 de las declaraciones americanas, todas ellas garantes de la libertad y seguridad individuales -como la jeffersoniana Declaración de Derechos de Virginia de 1776".

Existieron sin duda filósofos que influyeron en la concepción de un Estado libre del despotismo. Efectivamente, Jean Jaques Rousseau en su acreditado tratado político El contrato social o 
Principios de derecho político en 1762, presentó sus argumentos sobre libertad civil y ayudó a la ulterior ordenación y plataforma ideológica de la Revolución Francesa y las directrices constitucionales de Francia, al amparar la preeminencia de la voluntad popular, frente al derecho divino en que se basaba el monarca. Y es así, como la carta francesa

\section{(...) en el capítulo de los derechos} imprescriptibles del hombre la libertad viene primero, seguida de la propiedad, la seguridad y la resistencia a la opresión. Porque el Estado no tiene un fin en sí mismo; su razón de ser reside en la misión de conservar a los ciudadanos el disfrute de sus derechos; el soberano es el conjunto de la nación, que delega su autoridad en un gobierno responsable; la separación de poderes garantiza el fin de toda tentación absolutista. (Pierre, 1985, p. 58)

Las tesis Rousseaunianas enmarcadas en la libertad individual, se revelaron contrarias al despotismo de la Iglesia, al Estado en Francia y en toda Europa; dichas tesis se centró en el protagonismo de la voluntad de los individuos (Rousseau, 1983) a quienes les deben brindar las garantías necesarias por medio de constituciones que propendan por la Seguridad Jurídica reclamada por los ciudadanos. Con la revolución francesa, la expedición de su carta constitucional y posteriormente el Código Civil en 1804, se comprueba que

(...) el absolutismo tiene límites específicos en la medida en que el soberano está obligado a observar reglas de uso, llamadas leyes fundamentales del reino: así, las mujeres eran excluidas del trono, el rey debe ser católico, el rey no puede abdicar...pero su autoridad absoluta está limitada sobre todo por la multiplicidad de privilegios de los que gozan la nobleza y el clero. (Pierre, 1985, p. 20)

Con posterioridad a la expedición de la Constitución Francesa al cual se ha hecho referencia, se expide el Código Civil Francés, el cual trazó claros lineamientos legales en favor de la implementación del principio de Seguridad Jurídica señalado, con la imposición de límites al rey quien contaba con las facultades de administrar justicia, legislar, gobernar, "de administrar la hacienda, de declarar la guerra y de establecer la paz. Además nadie en la tierra le otorgaba todos los poderes al monarca; los tenía simple y llanamente por la "gracia de Dios" (Brewer-Carias, 2004. P. 126).

\subsection{El Código Civil Francés}

Con la expedición del Código Civil Francés en 1.804 o también llamado Código de Napoleón, como se denominaría en 1.807 , se percibe claramente la consagración del principio de Seguridad Jurídica. Se evidencia así en el Código descrito, la limitación al poder del Monarca, caracterizado por su arbitrariedad, mediante la disposición de normas que salvaguardan lo más sagrado como la libertad de las personas. Asimismo, se demuestra que "una clara manifestación de la Seguridad Jurídica es la ley escrita, debidamente dada a publicidad para conocimiento de todo el pueblo. Esa ley, formalmente sancionada, siempre ha sido objeto de respeto y obediencia, máxime en los regímenes democráticos donde se expresa la voluntad popular," (Urbano, 2007, p. 453) más no así en el régimen despótico trasgresor del principio de Seguridad Jurídica predominante antes de la Revolución Francesa.

Se reitera, que el principio de Seguridad Jurídica era íntegramente ignorado antes de la expedición tanto de la declaración de los derechos, como de la Constitución y del Código Civil Francés, por cuenta de los intereses sesgados del soberano y sus colaboradores. Adicionalmente, este principio se estatuye en el nuevo Código Civil Francés, bajo los fundamentos cardinales de libertad $e$ igualdad propios de la concepción liberal del derecho (Ferrajoli, 1995, p. 92), e ignorados precedentemente por los juzgadores franceses por las razones insistentemente señaladas.

En suma, los códigos napoleónicos se constituyeron en fuente de consagración del Principio 
de Seguridad Jurídica. Códigos que no obstante eran cuestionados por algunos como Savigny, quien los critica porque infería que el verdadero propósito de éstos eran expandirse por toda Europa, lo cual reprochaba por cuanto señalaba que el Derecho es un fenómeno cultural, que recubre un carácter establecido y propio de cada pueblo o nación (Savigni, 1986, p. 43).

Francia en ese momento (s. XVIII) se encontraba en una profunda crisis como resultado, entre otros, de la violación fragrante a la Seguridad Jurídica, no obstante desde el siglo XVII la monarquía de forma fallida, trató de implementar sistemas codificadores sin éxito alguno (Fernández, 2004). ¿Cómo iban a tener éxito si los códigos violaban principios como el de Seguridad Jurídica? Así las cosas, fue al ancien régime, término despectivo con el que los revolucionarios franceses se referían al gobierno anterior a la revolución, al que se le atribuyeron todas las irregularidades y contratiempos de la época, con la consecuente aparición del proceso revolucionario francés, que trajo consigo la expedición y ordenamiento de las leyes e implementación del principio de Seguridad Jurídica.

Por ende, lo que buscaba el grupo de redactores comisionados para estructurar el Código Civil Francés, era dirigir a este país a un estado donde imperase entre otros, el principio de Seguridad Jurídica; ¿y cómo lo lograrían? Con instrumentos para comprimir los desafueros del estado monárquico, como el mencionado Código Civil, donde se revela el principio referido.

Precisamente, se evidencia en el Discurso Preliminar del Código Civil Francés, que uno de los promotores de éste, Jean Etiene Marie Portalis, alcanzó a moldear las preocupaciones más relevantes de los ciudadanos de la época. Así, examina si la unificación del derecho en Francia es posible, teniendo en cuenta que "la experiencia prueba que los hombres cambian con mayor facilidad de dominación que de leyes" (Alterini, 2003). Portalis, en suma, pensaba que la unificación antes citada era deseable y fundaba sus argumentos en el incremento de la
Seguridad Jurídica que esto acarrearía, y que para la época, estaba sumamente cuestionada por los desmanes de la corona.

Es relevante señalar, que años antes a la Revolución Francesa, Montesquieu

(...) había relacionado las leyes con la naturaleza de las cosas, haciéndose precursor de la sociología. Indicaban los codificadores (liderados por Portalis), que un gran Estado a la vez agrícola y comercial como Francia, que poseía diversas industrias, no podía tener las leyes simples que podían bastar para una sociedad pobre o reducida. (Ciuro, 2007, p. 8).

Sólo presentaba problemas la forma de conciliar el derecho escrito con el consuetudinario y en ese sentido señaló que "es útil conservar todo lo que no es necesario destruir" (Alterini, 2003).

Se afirma que Montesquieu (1985) es pionero en estudiar y presentar las diferencias de las leyes con respecto a las divergencias de los pueblos como el francés. De hecho, se trata de un aporte significativo realizado por el jurista galo, en contraste con los contractualistas quienes no efectuaron análisis serios y reflexivos sobre los caracteres, climas, temperamentos, tipos de gobierno como el despótico reinante en Francia; el citado autor realizó grandes aportes incentivando el espíritu de libertad anhelado por los franceses ávidos de una revolución que garantizara entre otros, el principio de Seguridad Jurídica.

Por esta razón, se afirma que los tipos de gobierno dependen de factores como los antes señalados, que incitan a cambiar la forma de gobierno como en el caso de Francia; gobierno que incidía irregularmente en las decisiones de los jueces y donde el legislador no era necesariamente el más entendido en temas como el de la separación de poderes, implementado por Montesquieu, sino en moldear un pueblo por medio de leyes impositivas, acondicionadas a los intereses del ancien regime, lo que generó la movilización del pueblo en 1789 movido por el hambre. (Soboul, 1987, p. 198). 
Por ende, hay varios tipos de leyes que regulan las relaciones entre naciones, en el marco del derecho de gentes; el poder del Estado y el ciudadano, en el derecho público y entre particulares, en el derecho civil. Dichas leyes, deben adaptarse al tipo de régimen en que se encuentran, ya sea monárquico, republicano o despótico como el francés antes de la revolución. No obstante, no se puede dejar de lado el tipo de contexto, verbigracia, sí los ciudadanos están en el trópico y no les atrae el trabajo, es al Estado a quien le compete estructurar leyes para corregir esta falencia. Todo, con el fin de mejorar las condiciones del hombre y de su comunidad, como era el propósito de la Constitución y de los Códigos franceses.

En tal medida, se asevera que las leyes deben responder constantemente a las relaciones o fenómenos dinámicos coyunturales, pero siempre, la legislación debe centrarse en la Seguridad Jurídica y en su eficacia y esto se logra en la medida que haya una mayor atención a la realidad social (Montesquieau, 1985), como la vivida por los ciudadanos franceses.

Con la expedición del Código de Napoleón, como sería llamado en 1.807 , se percibe claramente la aplicación del principio de Seguridad Jurídica $y$ adicionalmente se fortalecen el de legalidad y derechos como el de defensa, a un juicio sin dilaciones injustificadas y principios como el de igualdad ante la ley, proporcionalidad, jurisdiccionalidad, lesividad, materialidad, carga de la prueba, necesidad de la pena e irretroactividad de la ley penal, con el fin de no convertir el proceso en un imperio liderado por el juez.

"En aplicación del Derecho ha de preferirse la legalidad" (Bernal y Montealegre, 2004, p. 27) señala el profesor Jaime Bernal Cuellar, entendido en materia penal (Fernández, 2004, p. 153), área que también fue tratada en el discurso preliminar del Código Civil francés, como una premisa fundamental del axioma nullum crimen sine lege, nulla poena sine lege, que garantiza igualmente al procesado la tan anhelada Seguridad Jurídica; la Legalidad tanto del delito como de la pena se erige como un principio que orienta el derecho penal y el procesal penal. Nullum crimen sine lege, nulla poena sine lege según el cual "nadie podrá ser investigado, juzgado y condenado por una conducta que no esté expresamente prevista como punible por la ley penal vigente al tiempo en que se cometió y conforme a la ley procesal vigente al momento de los hechos con observancia de las formas propias de cada juicio" (Forero, 2006). Formas que eran desconocidas al momento de juzgar a los ciudadanos franceses, quienes eran juzgados por conductas que ni siquiera estaban tipificadas como antijurídicas.

Se evidencia así, que con la expedición del Código referido, se limita el poder de un monarca arbitrario, con la disposición de normas que salvaguardan derechos fundamentales como la libertad de una persona; de esta manera,

una clara manifestación de la seguridad jurídica es la ley escrita, debidamente dada a publicidad para conocimiento de todo el pueblo. La ley formalmente sancionada, siempre ha sido objeto de respeto y obediencia, máxime en los regímenes democráticos donde se expresa la voluntad popular (Urbano, 2007, p. 453)

a diferencia de los regímenes despóticos como el francés con anterioridad a su revolución.

De la aplicación del principio de seguridad jurídica, en consecuencia, se desprenden principios relevantes como el de legalidad el cual se implantó en el texto del Código Civil francés; principio que cuenta con las siguientes ventajas que eran, son y serán aplicadas tanto en materia civil como en otras áreas del derecho.

Sin lugar a dudas, el principio de legalidad, desde sus orígenes, busca garantizar la igualdad, de todos lo asociados frente a la ley y por ello las expectativas del cumplimiento de las normas que en una sociedad radican en todos los ciudadanos, esto es, los asociados saben que no se harán distinciones odiosas (como se hacían antes 
de la expedición del Código de Napoleón) ni que prevalecerán los criterios de clase o condición social al momento de redactar ni al aplicar la ley...." (Forero, 2006, p. 48).

De la misma forma, con la expedición del Código Napoleónico a los justiciables se les brinda Seguridad Jurídica y en definitiva, se garantiza adicionalmente a todos los ciudadanos los derechos entre otros a la propiedad ${ }^{4} y$ libertad, en el entendido de que éstos solo serán limitados en el evento de contravenir las disposiciones establecidas por el ordenamiento jurídico (Forero, 2006).

La nueva concepción de las leyes con posterioridad a la expedición del nombrado Código, se centra en que éstas "no son puros actos de poder: son actos de prudencia, de justicia y de razón"(Portalis, 1997, p. 32). Todo ello, como prueba fehaciente de la necesidad de imponer límites al poder despótico de la época por medio de leyes útiles; resulta relevante indicar que en Inglaterra con Bentham (1950, p. 219) a la cabeza, se anunciaba la teoría del principio de utilidad, y se hacen importantes referencias en torno al deber de la ley como fuente de felicidad con el menor dolor. En cuanto a la Seguridad Jurídica, tema de este escrito, en lo atinente al derecho a la propiedad anhelado por el pueblo francés, se infiere que resulta imprescindible la preponderancia de la ley, para mantener dicha propiedad.

Tanto los comisionados y promotores del Código Civil francés como Portalis, Tronchet, BigotPréameneu Maleville, y Siéyes, habían leído y analizado a célebres pensadores, filósofos, juristas, como Cesare de Beccaria, Montesquieau (1985), Locke (Ciuro, 2007, p. 9) y Rousseau (Durkheim, 1985) entre otros y por tanto fueron

4 BENTHAM, Jeremy. Principio de Legislación y de Codificación. Madrid. Imprenta de D. Jordán, 1834. Tomo II. veamos: R. H. Barrow, Los romanos, Editorial. Fondo de Cultura Económica, México, 1950, p. 219; "la "pietas" era la voluntad de los dioses y la "utilitas" la finalidad perseguida mediante un acto" influenciados por sus teorías. El tratadista Soboul habla del objetivo al que tiende la revolución francesa citando a Robespierre (promotor de esta revolución), quien influenciado por los citados filósofos y juristas en su obra Rapport sur les príncipes de morale politique qui doivent guider la convention (1794) señala lo siguiente:

Queremos un orden de las cosas en el que todas las pasiones bajas y crueles sean encadenadas, todas las pasiones bienhechoras y generosas sean despertadas por las leyes (y)...que Francia, antaño ilustre entre los pueblos esclavos, eclipsando la gloria de todos los pueblos libres que han existido, se convierta en el modelo de las naciones, el pavor de los opresores, el consuelo de los oprimidos... (Soboul, 1987).

Asimismo, la influencia del jurista Beccaria era tan significativa que hasta la monarquía exaltaba sus teorías; Enrico Ferri señala que este autor "...con su pequeño maravilloso libro de los delitos y de las penas, había suscitado la víspera de la revolución francesa -un tan grande y clamoroso entusiasmo, igual entre los enciclopedistas que entre los príncipes reinantes en España, en Austria y Rusia..." (Ferri, s/f, p. 7). Por su parte, Hobbes, Rousseau y Locke encaminan su propuesta a proponer la garantía de la imparcialidad en los juicios a través de un tercero independiente sin influencia del monarca, planteando la necesidad apremiante de la existencia de una división de poderes (Durkheim, 1985) teoría que sería acogida y desarrollada por Montesquieu.

Montesquieu escritor y jurista francés nacido en 1689 y fallecido en 1755 , en su obra El espíritu de las Leyes, señala que el juzgador no debe desviarse de la ley, porque anularía el principio de alejamiento e independencia de los poderes que rigen una nación; como se demuestra, antes de la expedición del Código Civil Francés ya se presentaban teorías en torno a la limitación del poder y se hacían serias reflexiones como la 
de separación de poderes, entendida como un mecanismo de especialización funcional necesaria, máxime cuando estos períodos eran marcados por gobiernos déspotas donde proliferaba la total ausencia de independencia entre los poderes ejecutivo, legislativo y judicial.

En consecuencia lo primordial según Montesquieu, consistía en determinar las potestades del monarca y sus colaboradores, controladas mediante el sistema denominado de pesos y contrapesos, y como el inconveniente radicaba en el control del poder, él propone la fragmentación del mismo; a su vez, Beccaria concluiría que al juzgador, no le está permitido interpretar la ley, en tanto dicha interpretación, resultaría contraria a lo pretendido por el legislador.

La influencia de Locke sobre las bases de la Revolución Francesa, como de la estructura del Código Civil francés y por ende la implementación del principio de Seguridad Jurídica, son abordadas por el tratadista Miguel Angel Ciuro Caldani señalando que la codificación estuvo marcada por las ideas de Locke sobre "los derechos del hombre como requerimientos éticos de la personalidad en su desarrollo exterior, que constituían la base del orden civil" (Ciuro, 2007, p. 9); derechos centrados en la libertad y propiedad, considerada esta última como una "condición física de la libertad y manifestación de la razón y del querer sobre las cosas" (Ciuro, 2007, p. 9). Si bien es cierto la propiedad sobre bienes muebles adquirió relevancia, las normas señaladas en el Código civil francés, propendían por la promoción y protección del derecho a la propiedad inmobiliaria, ante todo de los pequeños propietarios de la tierra (Ciuro, 2007, p. 9).

Asimismo, a partir de una crítica iluminista "Voltaire pudo decir que existían en Francia ciento cuarenta costumbres que tenían fuerza de ley, todas ellas diferentes, y una persona que viajara en ese país cambiaría de ley con la misma frecuencia que su caballo cambiaría de lugar" (Ciuro, 2007, p. 251); sumado a lo anterior, se señala que el número de regímenes normativos vigentes en la Francia de 1789 era de trescientos sesenta y seis(Ciuro, 2007, p. 251).

Los redactores del Código de Napoleón fueron influenciados entonces por teorías como las rousseaunianas, las cuales señalaban que el derecho a castigar por parte de los juzgadores se sustentaba en la defensa social y la transformación de la venganza privada (Ferri, s/f, p. 14) en una justicia imparcial reclamada por los ciudadanos franceses. Ciudadanos que requerían "reformas procesales y penitenciarias que acabasen con la barbarie de los guardadores del preso sometido a la justicia, y con la arbitrariedad de los Jueces en la aplicación de penas, crueles y atentatorias a la dignidad humana".

Con la expedición del Código Civil Francés, y bajo las luces de asesores consagrados como Portalis "ciertamente uno de los propósitos fundamentales, era poner fin a la inseguridad jurídica del antiguo régimen e introducir un orden racional y sistemático (Fernández, 2004)". De la misma manera, se percibe claramente la aplicación del principio de Seguridad Jurídica, con lo que se garantiza al justiciado la aplicación de ésta, en el marco de la igualdad de todos frente a la ley y la protección del derecho inalienable a la libertad.

Por último, uno de los grandes temas a discutir, era la técnica legislativa que debía emplearse. Se postuló que "las leyes son hechas para los hombres y no los hombres para la leyes; ellas deben estar adaptadas al carácter, a los hábitos, a la situación del pueblo" (Ciuro, 2007, p. 8) en este caso el francés, que reclamaba seguridad en la aplicación de las normas que se establecían para regular sus relaciones. Se rechazó por parte de los redactores la idea de estructurar un código completo, que consagrara todas las situaciones que deberían ser sistematizadas en leyes. De esta manera se concluye, que la función de la ley es "fijar, a grandes rasgos, las máximas generales del derecho; establecer principios fecundos en consecuencias, y no descender en los detalles 
de las cuestiones que pueden originarse en cada materia" (Ciuro, 2007, p. 8).

\section{CONCLUSIONES}

Como resultado de la investigación bibliográfica realizada, se estableció que con anterioridad a la Revolución Francesa, no se implementó en debida forma el principio de Seguridad Jurídica, por cuanto eran numerosas y evidentes las irregularidades que se presentaban al impartir justicia a los ciudadanos franceses; anomalías que se reflejaban en la excesiva lentitud en los procesos y la designación tanto de legisladores, como juzgadores, en cargos de acuerdo a las conveniencias del monarca, quien gobernaba bajo un completo despotismo.

Se encontró que quienes impartían justicia, decidían las controversias presentadas, sustentados en los intereses del rey, porque de lo contrario se verían enfrentados a la muerte.

Se deduce que en respuesta a las mencionadas irregularidades, nace la Revolución Francesa que trajo consigo el establecimiento de la Declaración de Derechos de 1.789, la Constitución de 1.791 y el Código Civil Francés de 1.804; disposiciones en las cuales se implementa primordialmente el principio de Seguridad Jurídica y el de legalidad. Uno de los fines esenciales de dicha revolución, era organizar el sistema jurídico que operaba en aquella época, ubicando al individuo como sujeto de derechos sin discriminaciones y donde primara la supremacía de sus derechos, dentro del marco de la implementación del principio de Seguridad Jurídica.

\section{BIBLIOGRAFÍA}

ALEXI, Robert, (2007). Una Discusión Sobre la Teoría del Derecho. Editorial Marcian Pons. Madrid.

ALTERINI, Jorge A. (2003) Traducción del Discurso Preliminar del Código Civil Francés.
Editorial La Ley y Universidad de Buenos Aires. Buenos Aires.

BENTHAM, Jeremy. (1950) Principio de Legislación y de Codificación, Madrid, Imprenta de D. Jordán. 1834, Tomo II. veamos: R. H. Barrow, Los romanos, edit. Fondo de Cultura Económica. México.

BERNAL CUELLAR, Jaime. MONTEALEGRE LYNETT, Eduardo. (2004) El Proceso Penal, Universidad Externado de Colombia. Bogotá.

BREWER-CARIAS, Allan R. (2004). Reflexiones Sobre la Revolución Norteamericana (1776). La Revolución Francesa (1789), La Revolución Hispanoamericana (1810 - 1830), y Sus Aportes al Constitucionalismo Moderno. Bogotá: Editorial jurídica venezolana.

CIURO CALDANI, Miguel Angel. (2007) El Bicentenario del Código Civil Francés (Una Comparación Entre la Historia Jurídica Francesa y La Historia Jurídica Argentina) Universidad Nacional de Rosario. Argentina.

DURKHEIM E, (1985) Montesquieu y Rousseau. Precursores de la Sociología, Universidad Nacional, Bogotá. D.C. 1990. y MONTESQUIEU Chares L, Del Espíritu de las Leyes, Editorial Tecnos, Madrid.

FERNANDEZ ROJAS Gabriel. (2004) Francia: Seguridad Jurídica y Nueva Política Codificadora. Universidad Autónoma de México (UNAM) -Red de Revistas Científicas de América Latina y el Caribe. España y Portugal-.

FERRAJOLI, Luigi. (1995). Derecho y Razón. Trotta. Madrid.

FERRI, Enrico. (s.f) Sociología Criminal. Nueva Biblioteca Universal. Madrid.

FIORAVANTI, Maurizio. (2000) Los Derechos Fundamentales. Apuntes de Historia de las Constituciones. Editorial Trotta. 2000. Madrid.

FORERO RAMIREZ, Juan Carlos. (2006) Aproximación al Principio de Oportunidad. Grupo Editorial Ibáñez. Universidad del Rosario. Bogotá. 
JEAN ETIENNE, Marie Portalis. (1997) Discurso preliminar al Código Civil francés. Editorial Civitas. S.A. Madrid. España.

LÓPEZMEDINA, Diego Eduardo. (2006). ElDerecho de los Jueces. Legis Editores S.A. Bogotá. 2006.

MONTESQUIEU Chares L. (1985) Del Espíritu de las Leyes. Editorial Tecnos. Madrid.

PIERRE BOIS.Jean. (1985) La Revolución Francesa. Madrid.

PORTALIS, Jean Etienne Marie. (1997) Discurso preliminar al Código Civil francés. Editorial Civitas, S.A. Madrid. España.

ROUSSEAU, Jean Jacques. (1982) El Contrato Social. Editorial SARPE.
SÁNCHEZ DE LA TORRE, A. (1987) El Derecho en la aventura europea de la libertad. Editorial Reus. Madrid.

SAVIGNY, F. Von. (1986) De La Vocación De Nuestro Siglo Para La Legislación y la Ciencia Del Derecho, Los Grandes Maestros del Derecho, V. VII, Biblioteca Jurídica Heliastica.

SOBOUL, Albert. (1987) La Revolución Francesa. Principios Ideológicos y Protagonistas Colectivos. Barcelona. Editorial Crítica.

URBANO Salerno Marcelo. (2007) Calidad Institucional y Seguridad Jurídica: Pilares de la Constitución Civil, Editorial Academia Nacional de Ciencias de Buenos Aires. 